reared in a restricted environment. Journal of Comparative \& Physiological Psychology, 1970, 70, 157-164.

Montgomery, K., \& Zimbardo, P. Effect of sensory and behavioral deprivation upon exploratory behavior in the rat. Perceptual \& Motor Skills, 1957, 7, 223-229.

Neuringer, A. J. Animals respond for food in the presence of free food. Science, 1969, 166, 399-401.

Rosenzweig, M. R., Bennett, E. L., \& Diamond, M. C. Brain changes in response to experience. Scientific American, 1972, 226, 22-29.

Tarte, R. D., \& Snyder, R. L. Barpressing in the presence of free food as a function of food deprivation. Psychonomic Science $1972,26,169-170$

Walker, E. L. Psychological complexity as a basis for a theory of motivation and choice. In D. Levine (Ed.), Nebraska symposium on motivation Lincoln, Nebr: University of Nebraska Press, 1964. Pp. 47-96.

Woods, P. J., Fiske, A. S., \& Ruckelhaus, S. I. The effects of drives conflicting with exploration on the problem-solving behavior of rats reared in free and restricted environments. Journal of Comparative \& Physiological Psychology, 1961, 54, 167-169.

Zimbardo, P. G., \& Montgomery, K. C. Effects of "free" environmental rearing upon exploratory behavior. Psychological Reports, 1957, 3,589-594.

(Received for publication May 10, 1973.)

\title{
The effects of discrimination training on the recognition of white and oriental faces
}

\section{ELAINE S. ELLIOTT, ELIZABETH J. WILLS and}

ALVIN G. GOLDSTEIN

University of Missouri, Columbia, Mo. 65201

Recognition for faces of whites and orientals was investigated using white Ss at a predominantly white university. Ss who participated in a discrimination training, or practice, session involving a paired-associate (PA) task with oriental faces scored significantly higher on a subsequent recognition test involving oriental faces than did Ss who received no practice or Ss who received practice involving white faces. Ss who practiced with white faces did not score significantly higher on the recognition test than Ss without practice or Ss who saw oriental faces during the practice session. These results lend support to a differential experience hypothesis, with the possibility of schema functioning as a mediator of differential experience.

Maplass \& Kravitz (1969) attempted to demonstrate differential recognition performance for faces of own and other race among both white and black Ss from a 
predominantly black and predominantly white university. They found that white faces were recognized more often than were black faces, but that there was a significant interaction between race of $S$ and race of the stimulus. These findings are consistent with a hypothesis of differential experience with persons of other race and differential acquisition of cue utilization habits. However, the questionnaire data failed to show a correlation between reported experience and recognition performance. Alternatively, these authors suggested that the source of the difficulty in the recognition of the black face by white Ss lies in the darkness of the black face, which obliterates many discriminative details. However, in a study testing the recognition performance of black and white Ss for white, black, and oriental faces, Chance, Goldstein, and $\mathrm{McBride}^{1}$ found that whites recognized white faces best and oriental faces least, whereas blacks recognized black faces best and oriental faces least. The fact that oriental faces were less well recognized than black faces argues against the idea that poor recognition of black faces by whites lies in the darkness of the skin. These results are compatible with a differential experience hypothesis, since blacks and whites have had more experience with their own races and much less with the oriental race (the experiment was conducted at a Midwestern university).

Although the studies cited suggest a differential experience hypothesis as a possible explanation of differential recognition for faces of ethnic groups, they did not test this hypothesis directly by providing experimentally defined differential experience in discrimination. Results of other perceptual studies (e.g., Gibson, 1953) indicate that discrimination and recognition performance in general can be affected by prior experience through training.

The present study attempts to test the hypothesis that differential experience in making a discrimination between faces of a race different from S's will affect later recognition performance for faces of that race. A discrimination training, or practice, session will be conducted during which Ss will have to discriminate among a group of white faces or a group of oriental faces in a picture-number PA task. Assuming that white, midwestern college students have had little experience with orientals, the differential experience hypothesis will gain support if Ss given practice in discriminating between oriental faces score higher on a subsequent recognition task involving oriental faces than Ss who receive no training. Since these Ss will have had a great deal of experience in discriminating among white faces, their recognition performance for white faces should not be improved after discrimination training involving white faces.

\section{METHOD}

\section{Subjects and Design}

Sixty-six white students were recruited from an introductory psychology class to serve as Ss in partial fulfillment of course requirements. Ss were assigned randomly to one of six groups.
Twelve Ss participated in each of four discrimination training. or practice, groups. Two groups were involved in a discrimination task using white faces and were then tested on either white or oriental faces in a recognition task, and two groups were exposed to a discrimination task with oriental faces and were then given a recognition task involving either oriental or white faces. Two groups of 8 and $10 \mathrm{Ss}$ each were simply tested on a recognition task using white or oriental faces, respectively, to determine base-line recognition performance for the stimuli used in the experiment.

\section{Materials and Apparatus}

Stimuli used to determine base-line recognition and for testing recognition after practice were 80 black-and-white Caucasoid or oriental projected images. Half of the stimuli were female, and half were male. All photos showed a full-face view of the stimulus. A Carousel projector was used to present the slides.

An additional 30 Caucasian and 30 oriental faces mounted on $4 \times 6$ in cards were used in the PA task. In both sets of stimuli, each picture was mounted on one side of a card and a two-digit number (10 through 39) was paired with it on the other side of the card. The photos of white adults were obtained from a school district in the U.S., whereas the pictures of oriental adults were obtained from a newspaper article on China.

\section{PA Task \\ Procedure}

All Ss who were given practice via the PA task were tested individually. Each group of 30 white and 30 oriental stimuli was arbitrarily divided into three sets of 10 faces. Twenty-four Ss learned oriental picture-number PAs, whereas 24 learned white picture-number PAs. Ss were told that they would be given 10 cards at a time and that their task was to learn which face was paired with each number. Each $S$ was given approximately 2 min to study each set of PAs. E then showed each picture to $S$ for approximately $4 \mathrm{sec}$, during which time $S$ had to respond orally with the number paired with the picture. If $S$ failed to respond or responded incorrectly, $E$ said the correct number.

This procedure continued for either 10 trials or to a criterion of 2 consecutive errorless trials. The procedure was repeated for the remaining two sets of 10 cards. The oriental base-line and white base-line groups did not participate in the PA task.

\section{Recognition Test}

Both oriental base-line Ss and white base-line Ss were tested in groups, whereas Ss who received practice were tested individually immediately following the PA task. Ss were shown either 20 Caucasian or 20 oriental faces at a rate of 3-4 sec per slide. Ss were instructed to attend to the slides and nothing else. Recognition memory was measured immediately for all Ss and the method for testing recognition was the same for all groups.

In the recognition test, each $\mathrm{S}$ was shown a total of 80 stimuli for 3-4 sec each. Sixty of the slides were "new" (not seen before) and 20 were "old" (seen before). Presentation of old and new stimuli was random and identical for all Ss. Responses were recorded by $S$ on an answer sheet numbered 1-80, with two columns headed "Seen Before" and "Not Seen Before." S was never informed of his accuracy.

The problem of response bias was handled by explicitly instructing $S$ that of the 80 photos, exactly 20 would be "seen-before" items. Ss were asked to try to restrict the number of their seen-before responses to 20. Compliance with these instructions was facilitated by the single-page open format of the answer sheet, clearly numbered for 80 responses, which permitted $\mathrm{S}$ to readily count his seen-before responses.

\section{RESULTS AND DISCUSSION}

In a recognition study, false alarms are not of critical importance as long as the Ss comply with instructions to 
limit their "seen-before" responses to 20. The mean number of old responses, regardless of correctness, was 20 in the present study. This mean is very representative, since nearly all Ss restricted themselves to 18,19 , or 20 responses. Therefore, recognition scores of correct responses should be an adequate estimate of recognition here.

Means and standard deviations of the number of correct recognition responses made by each of the six experimental groups are presented in Table 1.

As expected, analysis of data showed that correct recognition performance of the group that viewed white faces without practice $(76.8 \%)$ was significantly better than the recognition performance of the group that viewed oriental faces without practice $[52 \%$; $t(16)=4.23, p<.01]$. These findings are in accord with other studies which have found that recognition performance for white faces is better than recognition performance for oriental faces by white Ss (Chance, Goldstein, \& $\mathrm{McBride}^{\mathbf{1}}$ ). The oriental group with practice in discriminating among oriental faces performed significantly better on the oriental recognition task $(68 \%)$ than did the group that was tested for recognition of oriental faces after practice with white faces $[57 \% ; \mathrm{t}(22)=2.15, \mathrm{p}<.05]$ and the group that was tested on oriental faces without practice $[52 \% ; \mathrm{t}(20)=3.07, \mathrm{p}<.01]$. This finding supports a hypothesis of differential experience in that $\mathrm{S}$ performed significantly better after gaining some experience in discriminating among oriental faces. Since the group that viewed white faces during practice and oriental faces during the recognition task did not perform significantly better than the group that viewed oriental faces during the recognition task without practice $[t(20)=.964$, $\mathrm{p}>.05]$, one can reject the idea that training enabled $\mathrm{S}$ to develop a set for learning, i.e., learning-to-learn or warm-up.

Further support for the rejection of warming up as a possible explanation for the improvement of the group that viewed oriental faces during practice and during recognition lies in the fact that significant performance differences were not found between the group that viewed white faces during recognition but who did not participate in the PA task $(76.8 \%)$ and the group that viewed white faces during both practice and recognition $[76 \% ; \mathrm{t}(18)=.177, \mathrm{p}>.05]$ or between the group that viewed white faces during recognition without practice $(76.8 \%)$ and the group that viewed oriental faces during practice and white faces during recognition $[78 \%$; $\mathrm{t}(18)=.187, \mathrm{p}>.05]$. Furthermore, a significant difference was not found between the groups that viewed oriental faces during both the PA test and the recognition test and the group that viewed white faces during both tests $[\mathrm{t}(22)=1.54, \mathrm{p}>.05]$. Positive transfer from the oriental PA test to the oriental recognition test and the lack of positive transfer from the white PA test to the white recognition test resulted in no significant difference between the two groups.
Table 1

Means and Standard Deviations of the Number of Correct Recognition Responses

\begin{tabular}{lcc}
\hline \multicolumn{1}{c}{ Group } & Mean & SD \\
\hline No Practice/Oriental Recognition & 10.40 & 2.412 \\
White Practice/Oriental Recognition & 11.41 & 2.503 \\
Oriental Practice/Oriental Recognition & 13.58 & 2.429 \\
No Practice/White Recognition & 15.37 & 2.559 \\
Oriental Practice/White Recognition & 15.58 & 2.353 \\
White Practice/White Recognition & 15.16 & 2.587 \\
\hline
\end{tabular}

Note-The maximum number of correct recognition responses possible is 20 .

The above findings are compatible with a differential experience hypothesis. It appears that the discrimination, which was of instrumental value in the oriental PA task, was sufficient to bring recognition for oriental faces equal to the recognition level for white faces. Perhaps this group developed a schema for the oriental face during practice. Through discrimination in the PA training task, Ss acquired a greater knowledge of the class of oriental faces. It is probable that through occasional exposure to orientals, Ss had a partial schema of the class of oriental faces, a notion of its central tendency, which allowed them to make between-group discriminations. However, as this schema did not satisfy a need, it remained suppressed (Vernon, 1955), while schema for white faces, which were instrumental in day-to-day experience, were built up. Through discrimination training with oriental faces, Ss acquired a knowledge of the schema's remaining characteristics (Attneave, 1957). They learned how individual oriental faces may differ (the properties and dimensions of variability) and how much individual oriental faces vary from the average or central tendency. Perhaps these are the parts of schema which allow for within-group discriminations.

In summary, this study of differential recognition performance for faces has indicated that recognition for oriental faces may be improved with practice in discriminating among oriental faces. These findings lend support to a differential experience hypothesis with schema functioning as an entity to mediate differential experience.

\section{REFERENCES}

Attneave, F Transfer of experience with a class-schema to identification-learning of patterns and shapes. Journal of Experimental Psychology, 1957, 54, 81-88.

Gibson, E. J. Improvement in perceptual judgments as a function of controlled practice or training. Psychological Bulletin, $1953,50,401-431$.

Malpass, R. S., \& Kravitz, J. Recognition for faces of own and other race. Journal of Personality \& Social Psychology, 1969, 13, 330-334.

Vernon, $M$. D. The functions of schemata in perceiving. Psychological Review, 1955, 62, 180-192.

\section{NOTE}

1. Chance, J., Goldstein, A. G., \& McBride, L. Faces and races: A series of explorations. Unpublished paper.

(Received for publication May 16, 1973.) 